\section{The Italian Co-Operation Response in Central America following Hurricane Mitch: Budgeted Priorities and Equity in Humanitarian Assistance P. Guglielmetti; A. Miozzo}

Ministry of Foreign Affairs, General Directorate for Development Co-Operation, Emergency Office, Rome, ITALY

On 29 October 1998, Hurricane Mitch first struck Central America and devastated Honduras and Nicaragua. It also hit Guatemala, El Salvador, Belize, and to a lesser extent, Costa Rica. At its peak, Mitch was the fourth-strongest hurricane recorded in the Atlantic. It affected an estimated 6.5 million people region-wide, of whom at least 2.5 million were left homeless. Estimates indicate that at least 11,000 people died and 10,000 still are missing. As an immediate response to this emergency situation, the Emergency Office of the Italian Co-operation provided a first-aid "package" consisting of food parcels, emergency relief items, and medical support, followed up by a second intervention that provided support to the victims in the following areas:

1) Health;

2) Water and sanitation;

3) Rehabilitation; and

4) Prevention of natural disasters.

The second aid package amounted to a total of US $\$ 6.4$ million (approximately 12 billion Italian lire) for the entire region.

The interventions were driven by the principal strategic and methodological approach of the Emergency Office of the Italian Co-operation during natural disasters. Considering the limited amount of the contribution, one of the major challenges was to ensure a balanced sheet of budgeted priorities, taking into consideration the emergency requirements of all of the countries affected. Under such a methodological approach, interventions were implemented in Honduras and Nicaragua (31\% and 27\% of the total budget, respectively), followed by Guatemala (24\%), El Salvador (15\%), and Belize (3\%). Both the magnitude of the event's impact on the population and the main needs of each country affected were the criteria used when allocating the available resources. The evaluation of the strategy to balance the contribution and the projects implemented through the emergency programme, demonstrated that simple criteria are useful to select the appropriate allocation strategy. Considering that in situations in which several countries are involved in the same disaster, economic realities make some emergencies more deserving than others. This suggests that some countries automatically will be favoured as being a recipient for humanitarian assistance and disaster relief.

Keywords: allocation; assistance; Central America; humanitarian; hurricane; medical; Mitch; priorities; support

\section{Can Mushroom Poisoning Be Considered as a Disaster?}

V.N. Padalka; Prof. I.P. Shlapak; S.M. Nedashkovsky; O.V. Kurashov; N.V. Alexeenko; A.G. Bogomol; Y.O. Polentsov

Kiev Medical Academy of Postgraduate Training, Ukrainian Center of Emergency and Disaster Medicine, Kiev, UKRAINE

Introduction: Mushroom poisonings in the Ukraine happen rather often: around 2,000 cases every year with mortality level of 100 patients per year, e.g., $5 \%$ of all cases. Since this pathology takes place only during a few months each year, and sometimes up to 20 victims come to this Center simultaneously: it seems like a disaster. This is the reason that patients with mushroom poisoning are treated in our city under the supervision of the Ukrainian Center of Emergency and Disaster Medicine (UCEDM).

Material and Methods: As can be seen from Table 1, 1,001 patients who were the most serious cases in the Ukraine were admitted to the UCEDM: $196 \mathrm{had}$ Amanita mushroom poisoning complicated with severe toxic hepatitis. A conventional treatment including penicillin, silibinin, plasmapheresis, etc. was given to them.

Table 1-Patients characteristics

$\begin{array}{ccccc}\text { Years } & \begin{array}{l}\text { Poisoned } \\ \text { Patients }\end{array} & \begin{array}{l}\text { Acute } \\ \text { Toxic } \\ \text { Hepatitis }\end{array} & \text { Deceased } & \begin{array}{l}\text { Mortality } \\ \text { Rate }^{*}\end{array} \\ \text { n } & \begin{array}{c}\text { n } \\ 93-99\end{array} 1,001 & 196 & 17 & (8.7)\end{array}$

*(toxic hepatitis)

Results: The mortality level was no worse than the published data for this category, even though we have no facilities to determine the amanitine level in biological liquids. Conclusion: The well-organized team cooperation in UCEDM including emergency physicians, toxicologists, intensivists, and the staff of the department of extracorporeal methods of detoxification, provided the appropriate level of care to victims with mushroom poisoning. Such a large number of victims and absence of the facilities for assessment of amanitine in biological liquids led us to the creation of the algorithm of mushroom poisoning management that will be discussed.

Keywords: amanitine; detoxification; emergency physician; extracorporeal; intensivist; mushroom; plasmapheresis; poisoning; toxicology; Ukraine

E-mail: polentsov@doctor.com 